\title{
Challenges Facing Faculty Members When Using a Learning Management System
}

\author{
Emad Abu-Shanab, Qatar University, Qatar \\ (iD) https://orcid.org/0000-0002-2826-883X \\ Jumana Samara, Qatar University, Qatar \\ Mohamed Arselene Ayari, Qatar University, Qatar
}

\begin{abstract}
Universities use learning management systems (LMS) to support teaching practices and add value to the educational system. A leading university in the gulf region (XYZ) provides support for faculty members (FMs) through its Center of Excellence in Teaching and Learning (CETL), where experts respond to their enquiries on how to use the LMS features. This study analyzed data available from such interactions and concluded that FMs preferred office (face-to-face) contacting method, assessment is the major generator of FMs enquiries, and also the majority of enquiries were clustered into five major dimensions. Full details and analyses are available in this study.
\end{abstract}

\section{KEYWORDS}

Challenges, Faculty Members, Gulf Region, Higher Education, Learning Management System

\section{INTRODUCTION}

Using learning management systems (LMSs) is becoming an integral part of educational systems and higher education infrastructure. The contribution of technology toward a better and more efficient system is undisputable. Universities are using LMSs for many objectives. Examples of such objectives are the reduction of teaching/learning cost, the opening of communication channels with students, the facilitation of the learning/teaching process and its eminent tasks, and the management and control of various processes for the purpose of analysis and decision-making. Using such systems will improve universities' performance and improve their image.

Universities try their best to make the adoption and implementation of such systems successful. The main stakeholders involved and interfacing with LMSs are students, instructors, and administrative staff in universities. Faculty members and students are the main users of the system. The success of such system in attaining universities' objectives is dependent on many factors among which users' acceptance is a major one. The adoption and use of LMSs by faculty members will open doors for their utilization and help in reducing costs, opening communication, and better control.

Faculty members face many challenges when using such systems and thus might avoid using them and lean towards traditional methods and channels. The use of LMSs by faculty members can

\section{DOI: 10.4018/IJICTE.2020100103}

This article, originally published under IGI Global's copyright on October 1, 2020 will proceed with publication as an Open Access article starting on January 25, 2021 in the gold Open Access journal, International Journal of Information and Communication Technology Education (converted to gold Open Access January 1, 2021), and will be distributed under the terms of the Creative Commons Attribution License (http://creativecommons.org/licenses/by/4.0/) which permits unrestricted use, distribution, and production in any medium, provided the author of the original work and original publication source are properly credited. 
be enhanced if universities identified such issues and challenges and addressed them properly. This study will try to explore the challenges facing faculty members, which prevent them from using LMSs or certain parts or functionalities.

The following section will review the literature, followed by a description of our research method. Section 4 will describe the data collection process, the analysis of data, and discuss the results and findings. Finally, our conclusions are stated in Section 5.

\section{LITERATURE REVIEW}

Information and communication technology (ICT) use in universities is not limited to LMSs; many studies are exploring the use of other channels and applications. Recent research focused on utilizing social media in conducting many educational activities (Aljasir, Bajnaid, Elyas, \& Alnawasrah, 2017; Madge et al., 2009; Moran et al., 2011), where such applications are becoming popular among faculty members and students. Other outlets like the Internet, e-mail, and other Web 1.0 or Web 2.0 tools are also utilized by universities in an attempt by faculty members and students to improve the learning process. This study will explore the use of a LMS as a major tool for educational activities. The following sections will try to summarize what the literature reported in this regard.

\subsection{Learning Management Systems}

Research reported that more than $90 \%$ of American universities use LMSs to offer academic programs (Al-Alak \& Alnawas, 2011). Learning management systems (LMSs) are portals that help instructors conduct various types of educational activities and reach students through a controlled domain. Universities use more than one system to facilitate the educational process like Learning Management System (LMS), Instructional Management System (IMS), Content Management System (CMS), and Student Information System (SIS) (Abu-Shanab et al., 2012).

LMSs help manage the practices and activities related to teaching and learning. Activities like registration, scheduling, facilitating and augmenting the communication between instructors and students, examination of available content, tracking students' performance, reporting performance to targeted stakeholders and students are examples of such cases (Yung-Ming, 2011). Recent versions of such systems are equipped with chat rooms, discussion forums, e-mail, and blogs. Furthermore, instructors can conduct detailed and rich assessments, perform surveys, and check attendance.

LMSs enable faculty to develop and deliver learning content, communicate with students, and enable open discussion (Kalinga, Bagile, \& Trojer, 2007). Some LMS applications are difficult for instructors to administer and use like organizing virtual office hours, automatically reminding students of their deadlines, and using group functionalities (Yueh \& Hsu, 2008).

Universities can benefit from open source portals like Moodle or Dokeos or many other available commercial and proprietary types if they pay their licensing and support costs. Example of famous LMSs available in the market are Blackboard, WebCT, or Atutor (Abu-Shanab \& Ababneh, 2015). Other examples of e-learning systems used in higher education are the following: TopClass, LearningSpace, Virtual-U, and FirstClass Classrooms.

$\mathrm{XYZ}$ is using one of the major LMSs in the market. It is mandatory for its faculty members to use the LMS to post content and grades. Faculty members are also encouraged to use other features such as announcements, assignments, discussion boards, online exams, attendance, etc. The university has recently grown to have nine colleges. It has around 20,000 students and above a thousand Faculty members. All new faculty members who join XYZ attend, as part of their orientation program, a mandatory training on how to use the different features of the LMS. The university offers ongoing workshops through the academic year to all faculty members on how to use intermediate and advanced features of the LMS. Tutorial videos and documents are available on the university website for their reference. They can also seek support by phone, email or office appointments with the LMS experts when they need help or have certain enquiries. 


\subsection{Benefits of LMS}

The major claimed purpose of using LMSs is to apply pedagogical policies and strategies in a more effective and efficient manner (Abu-Shanab \& Harb, 2011). As described earlier, LMSs can help universities, faculty members, and students in many activities. The list of activities provided by LMSs is endless. LMSs support most educational activities and the list is growing (Yung-Ming, 2011). The recent improvements on LMSs enable them to interact and interface with many applications to facilitate the learning process. Another study concluded that planning and building technological changes and integration into an organizational strategic planning process would ensure continuing and effective integration of technology in teaching (Yang \& Spear, 2017).

LMSs help faculty members manage their time to reach better efficiency and chances for innovation and creativity. Using administrative and educational tools available within LMSs, instructors can design, author, and develop instructional material and components to support the learning/teaching process (Abu-Shanab et al., 2012). The authors also emphasize the role of LMSs in facilitating an effective guidance and support, where instructors can interact with students and other associates using the available communication tools available through the system.

A study in the School of Education at the University of Alabama conducted few interviews with faculty members regarding the use of Blackboard, a popular LMS, and concluded to positive perceptions regarding the use of such systems. The author concluded that Blackboard might improve communications, nurture community sensation, and escalate productivity and expectations of students and faculty (Anderson, 2003).

Research also reported conflicting perceptions regarding their benefits. A study compared students and teachers perceptions and concluded that Eduwave, a Learning Management System, can attain university objectives, support teacher's role, support educational activities, influence students' learning process, and facilitate and improve communication and collaboration (Abu-Shanab, 2014). The author compared teachers and students perceptions and found that teachers perceive LMS as useful and trustworthy. On the other hand, students reported favorable perceptions towards the ease of use of Eduwave and their future intention to use the system.

\subsection{Challenges Facing Faculty Members}

Research related to technology adoption theories reported many factors that cause resistance or hinder organizational efforts to adopt such applications (Al-Alak \& Alnawas, 2011). LMSs are not an exception. Examples reported by the authors included perceived usefulness, perceived ease of use, knowledge, trust, social influence, and others. Research investigated many factors in an assumption that they might cause a challenge for faculty members. Similar results supported similar constructs proposed in the UTAUT model (Social influence, performance expectancy and effort expectancy) in predicting the intention to use technology in higher education institutions (Rosaline \& Wesley, 2017).

In a study in Newzealand, the researchers concluded that the major challenge facing faculty members is their ICT literacy (Nanayakkara, \& Whiddett, 2005). The study assumed that faculty members, with better knowledge and more experience, would demonstrate higher acceptance rates. The second contribution of the study is their conclusion that people are different in their adoption in early vs. late stages of system implementation. Another study proclaimed that using traditional face-to-face methods are more effective that using LMSs or electronic channels (James, 2008). The author conducted the study in Thailand and utilized a sample of faculty members in a process of investigating the challenges facing faculty members in adopting e-learning systems. Based on faculty members competencies, the author stressed the importance of training faculty members to better equip them with needed skills and bridge their resistance.

In alignment with the previously mentioned study, self-confidence was a major predictor of instructor's adoption of LMS. Another study indicated that age and job satisfaction are not influencing the adoption of e-learning systems (Tarhini et al., 2013). Furthermore, a study of 212 responses of faculty members in the USA concluded that ICT background is not a major determinant of technology 
adoption (Kamali, 2012). Finally, a study proclaimed that the nature of online learning requires faculty members to be more attentive and be prompt communicators, which rest heavier loads on their shoulders (Li \& Irby, 2008).

LMSs can cause substantial challenges with respect to technical issues, where major efforts by universities target faculty members to help them manage all types of activities. Still, some studies reported that faculty members need material that can be easily and semantically managed on LMSs (Davidson, 2005). In such situations, universities need to devote more effort and resources to support faculty members in accommodating their material and content requirements.

On the same line of argument, faculty members embracing such systems (using LMSs) require more advanced training if they need to implement certain activities. A study conducted in Poland concluded that teachers in general adopt LMSs but resist the use of activities that require an advanced skill (reported by less- experienced teachers). The study reported that (66\%) of teachers used LMSs for teaching, but less than (10\%) use LMS tools to support testing and assessment (Moscinska \& Rutkowski, 2010). Faculty members also reported that some LMSs require that they train students so they effectively and efficiently use the system (Coyner \& McCann, 2004). Faculty members reported that during online assessment, any deficiency in the process might cause a dilemma for faculty members. Taking the previous challenges into a higher level, the seamless integration of technology and pedagogy would become a big challenge for faculty members (Karsenti, 2001).

In the Middle East, a study in Saudi Arabia concluded that LMSs are popular and fully supported by faculty members, but reported low implementation and use. Such contradictory result might indicate some challenges facing universities and faculty members in using such systems (Hussein, 2011). The study also reported insignificant influence of gender and academic background in adopting such systems.

Another study, aiming to explore students attitudes toward online assessment using Blackboard (BB) grade center and assessment tools, proclaimed that faculty members' attitudes toward BB is influencing students motivation for embracing the system. The author of the article used the word "intricacies of the system" to describe BB assessment tools (Fageeh, 2015). The author recommended that more training be provided for instructors and students on the system. In addition, more language options are useful to facilitate certain types of courses. Finally, another study in Jordan revealed that the quality and involvement of users in implementing LMSs are the major obstacles facing universities. Faculty members reported that the two reasons are the major ones that hinder their adoption efforts (Altarawneh, 2011).

In conclusion, we can summarize that faculty face significant challenge when using a LMS. Reported reasons were conflicting, but can be summarized in the following: technical skills needed by faculty, training required for faculty and students, infrastructure adequacy and system efficiency, compatibility of system, and the integration of pedagogical objectives and technical characteristics of the LMS.

\section{RESEARCH METHOD}

This study explored the literature to better understand the challenges facing faculty members (FMs) in using the LMS. The majority of previous research focused more on the adoption of LMSs from a behavioral direction (refer to the previous sections), neglecting the functionalities of a specific LMS and how FMs use them. The use of an LMS improves the efficiency and effectiveness of the teaching/learning process, makes it convenient, and reduces the university cost. The use of any LMS by faculty members is accompanied by many challenges. Such challenges will hinder the use of such important systems by faculty.

This study tried to investigate the different functionalities of a specific LMS and the challenges facing FMs when using them. The view of data is reversed, where we utilized available data collected for the purpose of reporting the performance of the Center of Excellence in teaching and Learning 
(CETL) in XYZ university. In XYZ, faculty are encouraged to use the adopted LMS, where many resources are available for them like online courses and help files. In addition, The University offers training courses and one to one consultation through its CTEL.

Center of Excellence in teaching and Learning (CETL) is responsible of supporting academic staff at XYZ through different types of activities. One of these major activities is to organize workshops for FMs to help them be acquainted with available systems and improve their teaching and administrative performance. A set of these training workshops will focus on the use of the LMS at the university. Faculty members can also refer to the CTEL staff for some help by office appointments, phone or e-mail. Such support help faculty members when using the LMS and facilitate the adoption of such system.

The CTEL team keeps a record of such consultations and their proceedings. The data collected reveals many challenges facing faculty members when using such a tool for the purpose of managing the teaching process. The data used in this study was collected during the academic years 20142017 (Three academic years; 2014/2015, 2015/2016 \& 2016/2017). As mentioned, the purpose of collecting such data was for reporting and performance purposes. The data collected is tabulated using a spreadsheet application to make it easy for analysis and exploration. The following are the column headings of the available data: Date of contact, trainer, month, FM name, FM e-mail, FM College, contact method, Enquiry details, and comments. A manual clustering and summarization technique is implemented to conclude to the major challenges facing FM when using the LMS. The study analyzes other issues related to the consultation preferences, the college of FM, and other related issues.

This study is a descriptive one, where we tried to use the existing data to describe the challenges that FMs face when using the LMS. It is still imperative to keep in mind the other side of the coin when investigating the adoption of technology, i.e. behavioral and contextual factors. The technology adoption theories explored many factors like the system's usefulness and ease of use, the social influence, the infrastructure and environment, the risk and security issues, trust in technology, and other important factors. This study will take the functional view and see FMs challenges when using the LMS based on its functionalities and actual use. Such perspective is important as it exposes new perspectives and enrich our knowledge in this domain.

\section{DATA ANALYSIS AND DISCUSSION}

The first step in our analysis to organize and clean data to prepare for our use. The names and e-mails of FMs were removed from the file for privacy reasons. The college column was kept for further analysis. The second step was to clean data from mistakes and redundant terms. Examples of such redundancy and errors are the following: the names of colleges were used in different forms (acronyms vs. full names), the enquiry names were also misspelled or written differently (SafeAssign vs. Safe Assignment), or errors in some terms (quickly vs. qwickly). The data was also cleaned for missing values within the data records and for any type of contradiction with the set of known activities and tasks in this specific LMS.

After cleaning the data and merging the three files into one consolidated file. The resulting file included 424 enquiries. The analyses utilized pivot tables to classify the frequencies of data and summarize and cluster data into its final form. The list of unique enquiries distilled from the data set included 26 categories ranging from communication to assessment. Table 1 lists the enquiries categories and the method of contact. As mentioned, the CTEL trainers supported FM through multi-channel communication. They responded to enquiries through phone, e-mail, office visits, and after the training workshop. It lists the frequencies of enquiries per each category and per contact method. The grand total of columns and rows represents the total enquiries for each enquiry type of contact method.

We notice that the top five frequencies were all related to an assessment related category except one related to communication. The highest numbers of enquiries are related to grade center (119 
enquiries), test (97 enquiries), SafeAssign (48 enquiries), create assignment (26 enquiries), and the last is related to discussion boards/forums (22 enquiries).

Table 1 shows the data classified into five major dimensions based on the LMS major functionalities and our perspective of the topic. We listed the dimension names in the last column, where we summarized all enquiries' frequencies into these five dimensions. Such classification is limited by our data set, even though the LMS vendor reported their own classification of the overall functionalities into three: building courses, enhancing communication, and assessing learners. Our classification concluded to five categories: general and management, building courses, communication, assessment, and other tools. Once we had our categories in place, we classified all enquiries into the five dimensions. Then numbered them as shown in Table 1.

Table 1. Enquiry frequencies based on type and contact method

\begin{tabular}{|c|c|c|c|c|c|c|c|c|}
\hline \multirow[b]{2}{*}{$\#$} & \multirow[b]{2}{*}{ Enquiry Name } & \multicolumn{4}{|c|}{ Contact Method } & \multirow[b]{2}{*}{$\begin{array}{c}\text { Grand } \\
\text { Total }\end{array}$} & \multirow[b]{2}{*}{$\begin{array}{c}\# \\
\text { (freq) }\end{array}$} & \multirow[b]{2}{*}{ Dimension } \\
\hline & & \begin{tabular}{|c|} 
After \\
session \\
\end{tabular} & Email & office & Phone & & & \\
\hline 1 & Access \& Permissions & & 3 & 2 & 4 & 9 & \multirow{6}{*}{$\begin{array}{c}1 \\
(58)\end{array}$} & \multirow{6}{*}{$\begin{array}{l}\text { General and } \\
\text { Management }\end{array}$} \\
\hline 2 & BB Introductory & & 3 & 8 & 4 & 15 & & \\
\hline 3 & Course Avallabity & & 3 & 3 & 1 & 7 & & \\
\hline 4 & Course Customization/Style & & 1 & 1 & & 2 & & \\
\hline 5 & Groups/Users & 1 & 1 & 4 & 6 & 12 & & \\
\hline 6 & Qwickly Attendance & & 1 & 8 & 4 & 13 & & \\
\hline 7 & Camtasia Recording & & 1 & 5 & 1 & 7 & \multirow{4}{*}{$\begin{array}{c}2 \\
(19)\end{array}$} & \multirow{4}{*}{$\begin{array}{l}\text { Building } \\
\text { Courses }\end{array}$} \\
\hline 8 & Content & & & & 1 & 1 & & \\
\hline 9 & Content Area & & 2 & 3 & 4 & 9 & & \\
\hline 10 & Uploading Content & & 2 & & & 2 & & \\
\hline 11 & Announcements & & 1 & & 3 & 4 & \multirow{5}{*}{$\begin{array}{c}3 \\
(37)\end{array}$} & \multirow{5}{*}{ Communication } \\
\hline 12 & $\begin{array}{l}\text { Collaboration (Lecture Hall \& } \\
\text { Office Hours/chat) }\end{array}$ & & 2 & & 1 & 3 & & \\
\hline 13 & Discussion Board/Forums & & 1 & 19 & 2 & 22 & & \\
\hline 14 & Email & 1 & & 1 & 2 & 4 & & \\
\hline 15 & Notifications Dashboard & & 1 & 1 & 2 & 4 & & \\
\hline 16 & Assignment & & & 3 & 3 & 6 & \multirow{7}{*}{$\begin{array}{c}4 \\
(300)\end{array}$} & \multirow{7}{*}{ Assessment } \\
\hline 17 & Create Assignment & 1 & 3 & 11 & 11 & 26 & & \\
\hline 18 & Generating Reports & & 1 & & 1 & 2 & & \\
\hline 19 & Grade center & 2 & 8 & 69 & 40 & 119 & & \\
\hline 20 & SafeAssign & & 3 & 27 & 18 & 48 & & \\
\hline 21 & Surveys & & 1 & & 1 & 2 & & \\
\hline 22 & Tests & 1 & 14 & 50 & 31 & 97 & & \\
\hline 23 & Echo on BB & & 1 & 1 & & 2 & \multirow{4}{*}{$\begin{array}{l}5 \\
(9)\end{array}$} & \multirow{4}{*}{ Other Tools } \\
\hline 24 & Online Books & & & 1 & 1 & 2 & & \\
\hline 25 & Packages \& Utilities & & 3 & & 1 & 4 & & \\
\hline 26 & Tools area & & & 1 & & 1 & & \\
\hline & Grand Total & 6 & 56 & 218 & 142 & 423 & & \\
\hline
\end{tabular}


Extending our inspection to the dimension level, we can see that assessment was the highest enquired dimension (300 enquiries). Table 1 shows the grand total enquiries of each category and to what dimension it belongs. In addition, the \# (Freq.) column indicates the dimension number and the total number of enquiries reported. Less enquiries were reported in relation to building courses and other tools. To have a better understanding of this issue, the data should have included the time spent on each category. The number of enquiries might indicate a measure for the difficulty of dimension (and its categories) or the degree of use.

The second direction related to Table 1 is the contact method used. It seems that FMs prefer face-to-face interaction as the enquiries done through after session and office visits are 224 cases compared to 142 and 56 for phone and e-mails respectively (based on data in Table 1). Considering the preferred means of communication, phone channel has also a commonality with the face-to-face channels as it includes a synchronous nature. It seems that FMs are appreciating a fast and direct response from CTEL staff, where the direct channels dominated the channels available.

The second analysis done included the list of enquiries and the FM's college. Taking such analysis further will reveal the credentials of FM. In addition, the data used did not include the department of FM. The Blank column indicates a non-reported college for the FM, taking into consideration the diversity of contact method. The list of Colleges and their appreciations are listed in Table 2, Followed by Table 3, which includes the enquiries.

Table 2. Colleges appreciations used

\begin{tabular}{|l|l|}
\hline \multicolumn{1}{|c|}{ Acronym } & \multicolumn{1}{c|}{ College or Program Name } \\
\hline CAS & College of Arts and Sciences \\
\hline CBE & College of Business and Economics \\
\hline CCP & Core Curriculum Program \\
\hline CED & College of Education \\
\hline CENG & College of Engineering \\
\hline CHS & College of Health Sciences \\
\hline CLAW & College of Law \\
\hline CSIS & College of Sharia and Islamic Studies \\
\hline FP & Foundation Program \\
\hline CCP & Core Curriculum Program \\
\hline Other & Other centers and departments \\
\hline
\end{tabular}

The data included no enquiries from the College of Medicine, and the College of Pharmacy. In addition, we can see two columns that include other and blank. The blank column includes enquiries with no college or program reported. The other category includes other departments and centers not included or distinct from the lists colleges.

Table 3 shows that the highest numbers of enquiries are associated with CAS (242 enquiries) and the CBE (60 enquiries). On the other hand, we should report here that the largest colleges in XYZ based on student and FM numbers are the CAS and CBE. Such issue explains why we have such large number of enquiries.

Our investigation could not reveal any reasoning (other than size) for such frequency distribution as the type of college is not a well-defined criteria in this context. XYZ had jointly merged arts and sciences in one college. Also, some scientific college had less presence in the list even though they 
Table 3. Enquiry frequencies based on FM's College

\begin{tabular}{|c|c|c|c|c|c|c|c|c|c|c|c|c|}
\hline \multirow[b]{2}{*}{ Enquiry N ame } & \multicolumn{11}{|c|}{ College or Program } & \multirow{2}{*}{$\begin{array}{l}\text { Grand } \\
\text { Total }\end{array}$} \\
\hline & CAS & $\mathrm{CBE}$ & CCP & CED & CENG & CHS & CLAW & CSIS & FP & Other & (blank) & \\
\hline Access \& Permissions & 3 & 1 & & 1 & & & & & 2 & 1 & 1 & 9 \\
\hline BB Introductory & 11 & 2 & & 1 & & & & & & & 1 & 15 \\
\hline Course Availabity & 4 & 2 & & & 1 & & & & & & & 7 \\
\hline Course Cus tomization/Style & 1 & & & & & & & & 1 & & & 2 \\
\hline Groups/Use1s & 3 & 3 & & 1 & 3 & & & & & 2 & & 12 \\
\hline Qwickly Attendance & 8 & & & & 2 & & 2 & & 1 & & & 13 \\
\hline Camtasia Record ing & 3 & 3 & & & 1 & & & & & & & 7 \\
\hline Content & & & & & & & & 1 & & & & 1 \\
\hline Content Area & 5 & & & 1 & & & & & & 1 & 2 & 9 \\
\hline Uploading Content & & 2 & & & & & & & & & & 2 \\
\hline Announcements & 2 & 1 & & & 1 & & & & & & & 4 \\
\hline $\begin{array}{l}\text { Collaboration (Lec ture Hall } \\
\& \text { Office Hours/chat) }\end{array}$ & 1 & 1 & & & & & & 1 & & & & 3 \\
\hline Discussion Board/Forums & 16 & 1 & & 3 & & & & & & 1 & 1 & 22 \\
\hline Email & 2 & 1 & & & & & & & & & 1 & 4 \\
\hline Notifications Dashboard & & 1 & & 2 & & & & & & 1 & & 4 \\
\hline As signment & 2 & & & & 1 & & & & & & 3 & 6 \\
\hline Create Assignment & 17 & 4 & & 2 & & 1 & & 1 & & & 1 & 26 \\
\hline Generating Reports & & 1 & & 1 & & & & & & & & 2 \\
\hline Grad e center & 77 & 15 & 4 & 6 & 6 & & 2 & 1 & & & 8 & 119 \\
\hline SafeAssign & 31 & 5 & 2 & 4 & 4 & & & 2 & & & & 48 \\
\hline Surveys & & 1 & & 1 & & & & & & & & 2 \\
\hline Tests & 53 & 13 & & 4 & 2 & 2 & 2 & 8 & & 6 & 7 & 97 \\
\hline Echo on BB & & 1 & & & & & 1 & & & & & 2 \\
\hline Online Bools & & 1 & & & & & & & & & 1 & 2 \\
\hline Packages \& Utilities & 3 & 1 & & & & & & & & & & 4 \\
\hline Tools area & & & & & 1 & & & & & & & 1 \\
\hline Grand Total & 242 & 60 & 6 & 27 & 22 & 3 & 7 & 14 & 4 & 12 & 26 & 423 \\
\hline
\end{tabular}

might be perceived as similar (like CHS vs. College of Medicine or Pharmacy). Future research might try to cluster the enquiries into colleges and see what categories are more associated with a certain college or a certain contact method.

The last analysis done is related to the date of enquires. The data was labeled according to the month of enquiry and then the semester. The data was represented visually using a column chart to show the trend of frequencies change. Figure 1 depicts such results. The months are not sequential as the data did not include any enquiries in the month of July, and few were reported for the month of August (in all three years). Based on that the columns are 31 columns only. An increase in enquiries is witnessed in the third month of each semester. This can be explained by the start of assessment and midterm exam and the serious use of assessment activities.

Another column chart depicted the data according to semesters and is shown in Figure 2 and Table 4. The data indicates a rise in enquiries in Fall semester each year based on new recruitment and the extensive scheduled training for new faculty members. It is also visible that enquiries increase with time as more use of the LMS is expected. Finally, XYZ policies require that new faculty members attend some LMS workshops and use the LMS in their management of the teaching process. 
Figure 1. Enquiries related to month (ranked from August 2014 to June 2017)

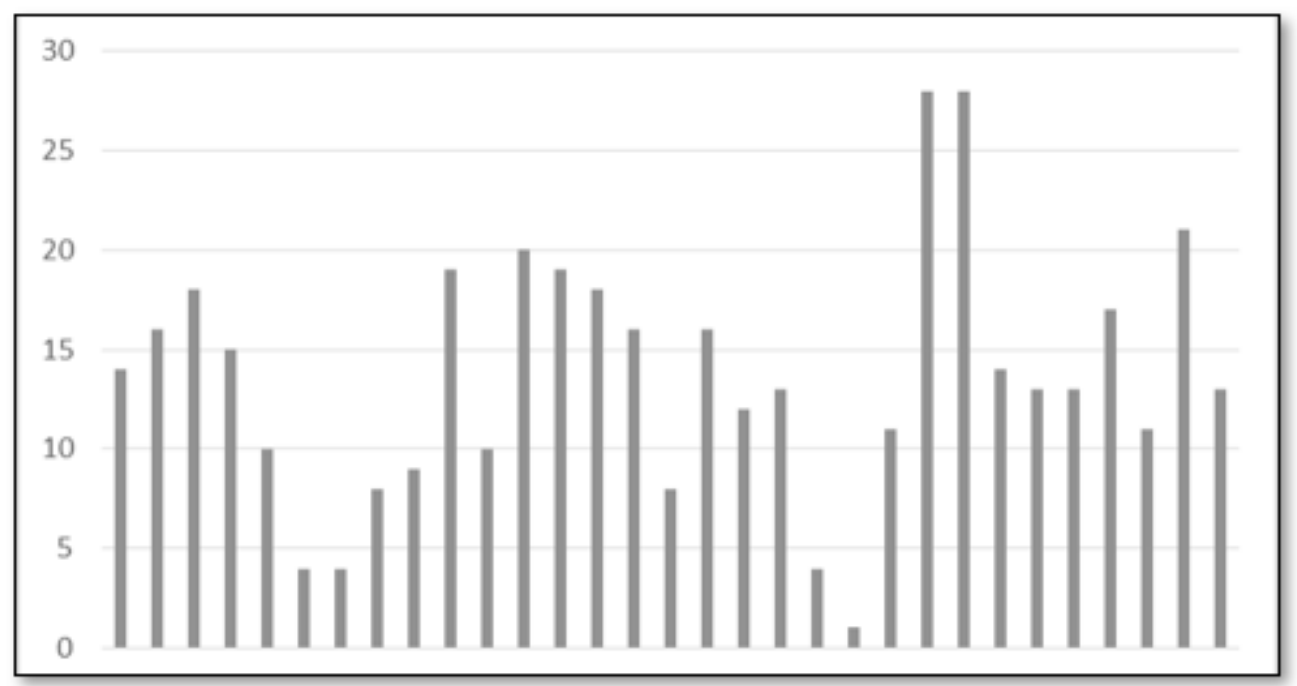

Figure 2. Column chart representing semester related data

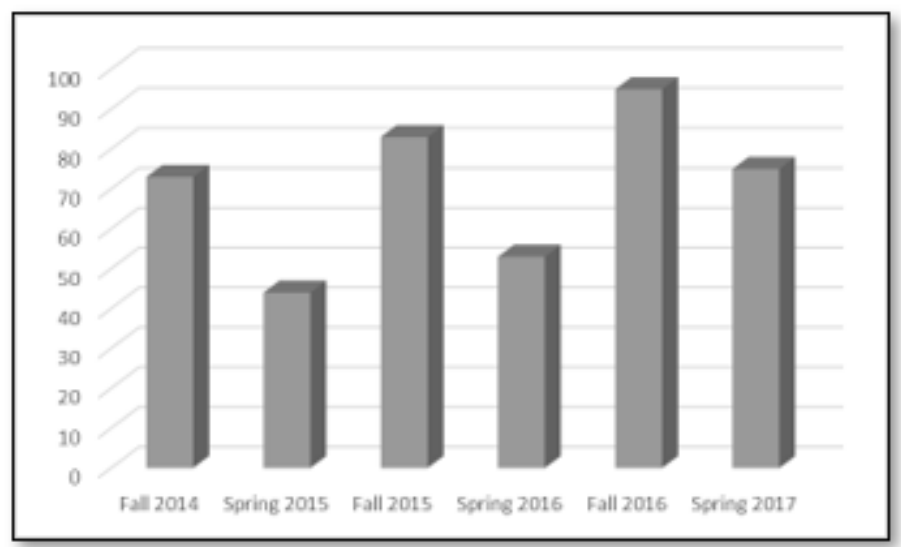

Table 4. Semester related data

\begin{tabular}{|l|l|}
\hline \multicolumn{1}{|c|}{ Semester } & \multicolumn{1}{c|}{ Enquiries } \\
\hline Fall 2014 & 73 \\
\hline Spring 2015 & 44 \\
\hline Fall 2015 & 83 \\
\hline Spring 2016 & 53 \\
\hline Fall 2016 & 95 \\
\hline Spring 2017 & 75 \\
\hline
\end{tabular}




\section{CONCLUSION}

Research on LMS is challenging, as it requires some type of accessibility to university data, which can be difficult in many cases. This study utilized previously collected data by a CTEL (Center of Excellence in Teaching and Learning at XYZ University). The data included the FMs enquiries during their use of the university LMS. The data spanned for three years and included 424 enquiries. The analysis of data focused on three main directions: First, the distribution of enquiries according to colleges. Second, the distribution of data according to contact method. Finally, the distribution of enquiries according to time. Results indicated that the majority of enquiries were from FMs from College of Arts and Sciences, and College of Business and Economics. Results also indicated that FMs preferred office (face-to-face) contacting method rather than other open channels of communication.

Finally, more enquiries were triggered during the Fall semester when compared to the Spring semester. The 26 categories reported in the data file were clustered into five major dimensions. The dimensions were general management of the learning/teaching process, building courses, communication, assessment, and other tools used. All previous results are summarized in Tables 5 and 6.

Table 5. Enquiries related to colleges clustered into the major five dimensions

\begin{tabular}{|l|c|c|c|c|c|c|c|c|c|c|c|}
\hline Dimension & CAS & CBE & CCP & CED & CENG & CHS & CLAW & CSIS & FP & Other & (blank) \\
\hline General and Management & 30 & 8 & 0 & 3 & 6 & 0 & 2 & 0 & 4 & 3 & 2 \\
\hline Building Courses & 8 & 5 & 0 & 1 & 1 & 0 & 0 & 1 & 0 & 1 & 2 \\
\hline Communication & 21 & 5 & 0 & 5 & 1 & 0 & 0 & 1 & 0 & 2 & 2 \\
\hline Assessment & 180 & 39 & 6 & 18 & 13 & 3 & 4 & 12 & 0 & 6 & 19 \\
\hline Other Tools & 3 & 3 & 0 & 0 & 1 & 0 & 1 & 0 & 0 & 0 & 1 \\
\hline Grand Total & 242 & 60 & 6 & 27 & 22 & 3 & 7 & 14 & 4 & 12 & 26 \\
\hline
\end{tabular}

Table 6. Enquiries related to contact method clustered into the major five dimensions

\begin{tabular}{|l|l|l|l|l|l|}
\hline \multicolumn{1}{|c|}{ Enquiry Name } & \multicolumn{1}{c|}{ After Session } & \multicolumn{1}{c|}{ Email } & \multicolumn{1}{c|}{ Office } & Phone & Total \\
\hline General and Management & 1 & 12 & 26 & 19 & 58 \\
\hline Building Courses & 0 & 5 & 8 & 6 & 19 \\
\hline Communication & 1 & 5 & 21 & 10 & 37 \\
\hline Assessment & 4 & 30 & 160 & 105 & 300 \\
\hline Other Tools & 0 & 4 & 3 & 2 & 9 \\
\hline Grand Total & 6 & 56 & 218 & 142 & 423 \\
\hline
\end{tabular}

Based on the previous results, this study concluded that assessment is the major generator of FMs enquiries. In addition, CTEL can conduct focused sessions for the two major colleges to support FMs in their locations and encourage them to use the LMS. The research team, and based on the examination of the communication channels open for FMs to contact the CTEL trainers, recommends opening a discussion board (or a forum) that make available all enquiries to all members and open a direct synchronous channel. Even though the major contact methods are related to face-to-face medium, still, a discussion forum open for FMs will reduce the number of enquiries and help reduce 
common categories. CTEL trainers need to understand that the limitation associated with forums is that FMs might not accept revealing their identity. Such a limitation might hinder such channel. A "Frequently Asked Questions" page (FAQ) is another recommendation that can solve the issue of identity and can include answers to many common questions.

\subsection{Contribution of Research}

As we mentioned earlier, research on actual data related to faculty members' use of LMS is challenging. Many universities are keen on providing access to such data for the purpose of research. This study is the first to examine the adoption challenges of a specific LMS based on data related to its functionalities. Results revealed important insights around the frequencies of enquiries among colleges and contact methods. We also gained important insights of FM preferences on their preferred contact channel. Finally, this study utilized real data based on a long period of time that mapped and revealed important conclusions on the topic of interest.

One of the major contributions of this study is its longitudinal perspective, where data was collected during the years 2014-2017. Such perspective is rich, where a collective image of the issues discussed in the conclusions and the previous paragraph of this subsection is formulated. One of the major initiatives of the university is to open all needed material for faculty members online, which neglects the F2F interaction requested by substantial portion of FMs. This result supports the findings of (Budu, 2018), where their qualitative analysis concluded that subjects might be keen on opening their mind in an online environment and prefer F2F settings for convenience. They also stressed the anonymity aspect, which might be at risk if we use the formal e-mails/channels of university.

\subsection{Limitations and Future Work}

This study suffered from its small sample size and simple data set collected. The richness of behavioral studies is lacking, but was compensated by the data type and its originality. This study utilized secondary data that was collected for the purpose of reporting and performance. Future work can add more dimensions to the existing data, where clustering techniques can be utilized to come up with certain categories related to certain colleges or contact methods. One of the approaches to explore such direction of research is to design a different research instrument to capture such proposed dimensions.

The other direction of research is to control for the role of the training office and directly contact faculty and explore their perceptions regarding the research questions. Future work can also utilize scale related data that can depict the interactions of diverse constructs in this domain. 


\section{REFERENCES}

Abu-Shanab, E. (2014, October-December). E-learning System's Acceptance: A Comparative Study International Journal of Web-Based Learning and Teaching Technologies, 9(4), 1-13. doi:10.4018/ijwltt.2014100101

Abu-Shanab, E., \& Ababneh, L. (2015, March). Exploring Academicians Acceptance of E-Learning Using an Extended TAM: The Case of Yarmouk University. Journal of Network Communications and Emerging Technologies, 1(1), 6-10.

Abu-Shanab, E., Ababneh, N., \& Momani, A. (2012). E-learning Systems' Acceptance: The Case of Eduwave in Jordan. In Proceedings of the 8th International Scientific Conference eLearning and software for Education (pp. 463-467). Academic Press.

Abu-Shanab, E., \& Harb, Y. (2011). E-learning in Jordanian Universities, the Case of Al-Hashemite University. In Proceedings of the 5th International Conference on Information Technology. Academic Press.

Al-Alak, B. \& Alnawas, I. (2011). Measuring the Acceptance and Adoption of E-Learning by Academic Staff. Knowledge Management \& E-Learning: An International Journal, 3(2), 201-221.

Aljasir, S., Bajnaid, A., Elyas, T., \& Alnawasrah, M. (2017). Facebook’s Compatibility, Reasons for Disclosure, and Discussion of Social and Political Issues: The Case of University Students Using Facebook. Journal of Management and Strategy, 8(5), 1-17. doi:10.5430/jms.v8n5p1

Altarawneh, H. (2011). A Survey of E-Learning Implementation Best Practices in Jordanian Government Universities. International Journal Of Advanced Corporate Learning, 4(2), 9-17.

Anderson, J. (2003). Faculty Perspectives of the Blackboard Course Delivery System. Presented at the Annual Meeting of the Mid-South Educational Research Association. Academic Press.

Budu, J. (2018). What Makes Learners Share Feedback or Not in an Online Community for Education. International Journal of Information and Communication Technology Education, 14(2), 48-59. doi:10.4018/ IJICTE.2018040104

Coyner, S.C., \& McCann, P. L. (2004). Advantages and challenges of teaching in an electronic environment: The Accommodate model. International Journal of Instructional Media, 31, 223-228.

Davidson, M. (2005). Distance education in high schools: Benefits, challenges, and suggestions. The Clearing House: A Journal of Educational Strategies, Issues and Ideas, 78(10), 105-108.

Fageeh, A. (2015). EFL student and faculty perceptions of and attitudes towards online testing in the medium of Blackboard: Promises and challenges. JALT CALL Journal, 11(1), 41-62.

Hammouri, Q., \& Abu-Shanab, E. (2018). Exploring Factors Affecting Users' Satisfaction Toward E-Learning Systems. International Journal of Information and Communication Technology Education, 14(1), 44-57. doi:10.4018/IJICTE.2018010104

Hussein, H. (2011). Attitudes of Saudi Universities Faculty Members towards Using Learning Management System (JUSUR). Turkish Online Journal Of Educational Technology, 10(2), 43-53.

James, P. (2008). Academic Staff Perceptions Of ICT And E-learning A Thai He Case Study. The Turkish Online Journal of Educational Technology, 7(4), 36-44.

Kalinga, E., Bagile, B., \& Trojer, L. (2007). An Interactive e-Learning Management System (e-LMS): A Solution to Tanzanian Secondary Schools' Education. World Academy of Science, Engineering and Technology International Journal of Information and Communication Engineering, Vol, 1(3), 46-49.

Kamali, A. (2012). Antecedents of Adopting e-Learning: Toward a Model of Academic e-Learning Acceptance Culture. In Proceedings of the Information Systems Educators Conference. Academic Press.

Karsenti, T. (2001, Summer). From blackboard to mouse pad: Training teachers for the new millennium. Education Canada, 41(2), 32.

Li, C., \& Irby, B. (2008). An Overview Of Online Education: Attractiveness, Benefits, Challenges, Concerns And Recommendations. College Student Journal, 42(2), 449-458. 
Madge, C., Meek, J., Wellens, J., \& Hooley, T. (2009). 'Facebook, social integration and informal learning at university: 'It is more for socialising and talking to friends about work than for actually doing work'. Learning, Media and Technology, 34(2), 141-155. doi:10.1080/17439880902923606

Moran, M., Seaman, J., \& Tinti-Kane, H. (2011). Teaching, Learning, and Sharing: How Today's Higher Education Faculty Use Social Media. Boston, MA: Babson Survey Research Group.

Moscinska, K., \& Rutkowski, J. (2010). Barriers to Introduction of e-learning: a Case Study. In Proceedings of the IEEE Global Engineering Education Conference (EDUCON) - "Learning Environments and Ecosystems in Engineering Education.” Academic Press.

Nanayakkara, C., \& Whiddett, R. J. (2005). A model of user acceptance of e-learning technologies: A case study of a Polytechnic in New Zealand. Presented in 4th International Conference on Information Systems Technology and its Application (ISTA 2005). Academic Press.

Rosaline, S., \& Wesley, J. R. (2017). Factors Affecting Students' Adoption of ICT Tools in Higher Education Institutions: An Indian Context. International Journal of Information and Communication Technology Education, 13(2), 82-94. doi:10.4018/IJICTE.2017040107

Tarhini, A., Hone, K., \& Liu, X. (2013). Factors Affecting Students' Acceptance of e-Learning Environments in Developing Countries: A Structural Equation Modeling Approach. International Journal of Information and Education Technology, 3(1), 54-59. doi:10.7763/IJIET.2013.V3.233

Yang, D., \& Spear, C. (2017). The effects of faculty status, faculty gender, field of study, and class size on the use of blogs, wikis, and discussion boards. International Journal of Information and Communication Technology Education, 13(2), 52-64. doi:10.4018/IJICTE.2017040105

Yueh, H., \& Hsu, S. (2008). Creating a learning management system to support instruction. Communications of the ACM, 51(4), 59-63. doi:10.1145/1330311.1330324

Yung-Ming, C. (2011). Antecedents and consequences of e-learning acceptance. Information Systems Journal, 21(3), 269-299. doi:10.1111/j.1365-2575.2010.00356.x

\begin{abstract}
Emad A. Abu-Shanab earned his Ph.D. in business administration in the MIS area from Southern Illinois University - Carbondale, USA, his MBA from Wilfrid Laurier University in Canada, and his bachelor's in civil engineering from Yarmouk University (YU) in Jordan. His research interest in areas like e-government, technology acceptance, e-marketing, E-CRM, the Digital Divide, e-CRM, IT project management, and e-learning. He has published many articles in journals and conferences, and authored three books in e-government, and few book chapters. Dr. AbuShanab worked as an assistant dean for student affairs, quality assurance officer in Oman, and the director of Faculty Development Center at YU. He is a professor in the MIS Department and was the department chair. Now Dr. Abu-Shanab works at Qatar University in the accounting and Information Systems Department.
\end{abstract}

Jumana Samara holds a master's degree in Computer Science from the American University, Washington DC, USA and a Bachelor of Computer Engineering from Yarmouk University, Jordan. After teaching computer science for 11 years, Jumana is currently the manager of training and educational technology at the Center of Excellence in Teaching and Learning (CETL) at Qatar University (QU), where she plans and facilitates education-technology training programs for faculty members.

Arslene Ayari holds a Ph.D. from the College of Engineering in the University of Colorado at Boulder and a master's degree from Ecole Polytechnique De Montreal, Canada. He is the director of the center for excellence in teaching and learning at Qatar University (QU) where he leads the efforts to implement effective pedagogies and innovative educational technology solutions. He is a faculty of graduate studies at the college of engineering, Qatar University. 